\title{
Summary of Infection Control in the Dental Office: A Global Prospective
}

\author{
Louis G. DePaola and Leslie E. Grant
}

The practice of dentistry is very demanding. Patients must be scheduled, supplies ordered, staff issues dealt with, and numerous other details must be worked out each and every day. With such a high level of activity, there is a tendency to cut corners to fit everything in to the daily schedule. Unfortunately, when this occurs, something is compromised. In the area of infection control, any lack of compliance with published guidelines can result in a significant risk for disease transmission and patient safety [1, 2]. While transmission of infectious agents in dental settings is rare in developed countries, it can and does occur [3-5]. For example, in the USA, a number of documented breaches of infection control in at least four states have been reported between 2012-2013. In each of these cases, patients have been advised to be tested for blood-borne infections which included Human Immunodeficiency Virus (HIV), hepatitis B virus (HBV), and hepatitis C virus (HCV). In each case, the dentist was sanctioned for not following recommended infection control practices.

\subsection{The Importance of Infection Control}

What happens when we ignore the principles of microbiology and infection control? Diseases are transmitted, people get sick, and some may die. Careers can be ruined. The importance of infection control simply cannot be overstated. The microbial threats facing us today are significant, and the situation is not likely to improve.

\footnotetext{
L. G. DePaola $(\bowtie)$

Department of Oncology and Diagnostic Sciences, School of Dentistry,

University of Maryland, Baltimore, MD, USA

e-mail: ldepaola@umaryland.edu

L. E. Grant

National Dental Association, Glen Arm, MA, USA

e-mail: legrant@comcast.net
} 
Highly resistant organisms are now commonplace and are the cause of health-careassociated infections (HAIs) throughout the world. In the USA, an estimated 1.7 million HAIs occur each year contributing to the death of almost 100,000 patients, and HAIs have emerged to become the fourth leading cause of death in the USA and kill more people each year than AIDS, breast cancer and auto accidents combined $[6,7]$. Approximately $5-10 \%$ of hospitalized patients in the developed world acquire such infections [8]. The rates of HAIs is much higher in underdeveloped countries [8]. A great majority of these infections are preventable. Proper use of hand hygiene is critical to the prevention of many of these infections [8]. However, compliance among HCWs is poor; usually below 40\% [8, 9]. Regardless of the country where dental care is rendered, the dentist has the moral, legal, and ethical responsibility to practice dentistry in as safe a manner as possible.

As explained throughout this publication, almost everything in a health-care setting can serve as a reservoir and a vector for opportunistic pathogenic organisms. This includes but is not limited to: surfaces, hands of HCWs, and medical/dental equipment and/or devices $[1,2,10]$. Factors that increase the acquisition of infections in any health-care setting, inclusive of dental, include:

- The persistence of some bacteria and viruses on inanimate objects and surfaces for days, weeks, and months.

- The lack of compliance with hand hygiene recommendations.

- Breaches in evidence-based infection prevention practices.

- The tendency to cut corners by existing staff.

- Inadequate or flawed training.

- The growing volume of patients admitted in acute-care hospitals.

- The growing shortage of health-care professionals.

- Poor sanitation in health-care facilities $[1,2,10]$.

Surfaces have been shown to play a significant role in the acquisition, persistence, and spread of infections. Clinically important microorganisms that can cause HAIs have been shown to persist in the environment for considerable periods of time [11]. This facilitates the spread of the organism throughout a health-care (dental) facility, especially when compliance with hand hygiene is poor. Contaminated hands have been shown to be the vector for the contamination of viruses to multiple surfaces or patients and can also be the source of recontaminating the surface that has been previously disinfected [11]. Across the globe, evidence documents low compliance with hand hygiene making the risk from contaminated surfaces a significant factor in disease transmission in medical and dental facilities. Figure 15.1 clearly illustrates how a contaminated surface with low hand hygiene compliance can put a patient a risk for the transmission of pathogenic viruses, bacteria, fungi, and other microorganisms [11]. Proper cleaning and disinfection of surfaces is essential to prevent the contamination and spread of infectious organisms in all dental settings.

Another factor that increases the risk of disease transmission in medical/dental setting is the persistence of many pathogens in the health-care environment. Viruses from the respiratory tract (coronavirus, coxsackievirus, influenzavirus, SARS virus, 


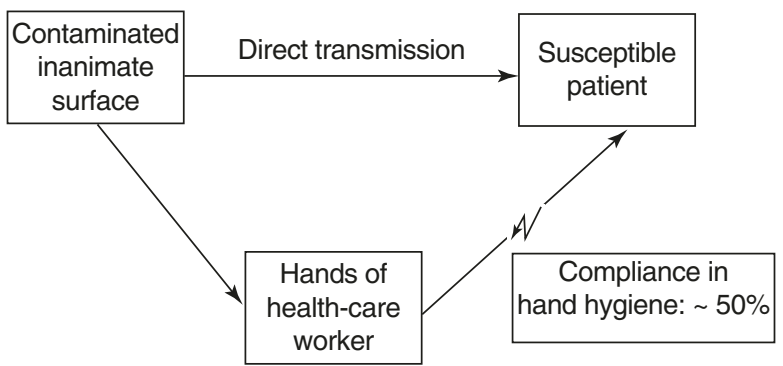

Fig. 15.1 Common modes of transmission from inanimate surfaces to susceptible patients. (Adapted from: Kramer et al. BMC Infectious Diseases 2006 6:130. doi:https://doi. org/10.1186/1471-2334-6-130 [11])

and rhinovirus) can persist on surfaces for a several days. Blood-borne viruses (HBV or HIV) can persist for more than 1 week [11]. Herpes viruses such as CMV or HSV type 1 and 2, commonly encountered in the dental office, persist on surfaces for a few hours up to 7 days [11]. However, viruses from the gastrointestinal tract (astrovirus, HAV, poliovirus, and rotavirus) can persist for approximately 2 months [11]. Bacteria can persist for much longer periods of time. Most Gram-positive bacteria can survive for months on dry surfaces and many Gram-negative species can also survive for weeks to months [11]. Table 15.1 illustrates this phenomenon.

\subsection{Disease Transmission in the Dental Office}

Although the transmission of infectious diseases in all health-care settings, including dental, has been well documented, many dental offices DO NOT follow recommended infection control standards. Patients are put at risk for disease transmission in the dental office because of:

- Cross contamination.

- Unsafe injection practices.

- Lack of personal protective equipment and hand hygiene.

- Incomplete or total lack of instrument cleaning.

- Improper biological monitoring of sterilizers.

- Inability to perform and/or verify sterilization $[1,2,10]$.

Table 15.1 Persistence of clinically relevant bacteria on dry inanimate surfaces

\begin{tabular}{|l|l|}
\hline Acinetobacter spp. & 3 days to 5 months \\
\hline Clostridium difficile (spores) & 5 months \\
\hline Escherichia coli & 1.5 h to 16 months \\
\hline Pseudomonas aeruginosa & 6 h to 16 months \\
\hline Serratia marcescens & 3 days to 2 months \\
\hline Staphylococcus aureus & 7 days to 7 months [11].
\end{tabular}

Adapted from: Kramer et al. BMC Infectious Diseases 2006 6:130. doi:https://doi.org/10.1186/1471-2334-6-130 [11] 
In order to prevent the transmission of infectious disease in the dental office, infection control recommendations have been formulated. While there is no universal global guideline, most countries as explained in the eleven chapters in this publication have clear-cut guidelines that dentists can follow to prevent the spread of infectious diseases during the delivery of dental care. It is the hope of all of the authors of this publication that their contributions can help the dental practitioners around the globe to understand the importance of infection control in the dental office and incorporate the principles of infection control/disease prevention presented in Chaps. 1-14 into their dental practices.

\section{References}

1. Centers for Disease Control and Prevention (CDC). Guidelines for infection control in dental health-care settings guidelines for infection control in dental health-care settings. MMWR. 2003;52(RR17):1-61. http://www.cdc.gov/mmwr/preview/mmwrhtml/rr5217a1.htm. Accessed Aug 2013.

2. Centers for Disease Control and Prevention (CDC). Guide to infection prevention for outpatient settings: minimum expectations for safe care. 2011. http://www.cdc.gov/HAI/pdfs/guidelines/standatds-of-ambulatory-care-7-2011.pdf. Accessed Aug 2013.

3. FDI infection control in dental practice. http://www.fdiworlddental.

4. Royal College of Dental Surgeons of Ontario November. Infection prevention and control in the dental office. 2009. p. 4-49.

5. Centers for Disease Control and Prevention. Summary of infection prevention practices in dental settings: basic expectations for safe care. Atlanta, GA: Centers for Disease Control and Prevention, US Dept. of Health and Human Services; 2016. p. 1-414.. Adapted from: Guide to infection prevention for outpatient settings: minimum expectations for safe care. http://www. cdc.gov/hai/settings/outpatient-care-guidelines.html.

6. Klevens RM, Edwards JR, Horan TC, Gaynes RP, Pollack DA, Cardo DM. Estimating health care-associated infections and deaths in U.S. hospitals, 2002. Public Health Rep. 2007;122:160-6.

7. Scott RD. The direct medical costs of healthcare-associated infections in U.S. hospitals and the benefits of prevention. 2009. http://www.cdc.gov/HAI/pdfs/hai/Scott_CostPaper.pdf.

8. WHO. WHO guidelines on hand hygiene in health care. Geneva: World Health Organization; 2009. http://whqlibdoc.who.int/publications/2009/9789241597906_eng.pdf.

9. Longtin Y, et al. Hand hygiene. N Engl J Med. 2011;364:e24. http://vigigerme.wordpress. com/2011/04/06/new-england-journal-of-medicine-features-hand-hygiene-video/. Accessed Aug 2013.

10. Collins AS. Preventing health care-associated infections. In: Hughes RG, editor. Patient safety and quality: an evidence-based handbook for nurses. Rockville, MD: Agency for Healthcare Research and Quality (US); 2008. http://www.ncbi.nlm.nih.gov/books/NBK2683/. Accessed Aug 2013.

11. Kramer A, et al. How long do nosocomial pathogens persist on inanimate surfaces? A systematic review. BMC Infect Dis. 2006;6:130. http://www.biomedcentral.com/1471-2334/6/130. Accessed Aug 2013. 